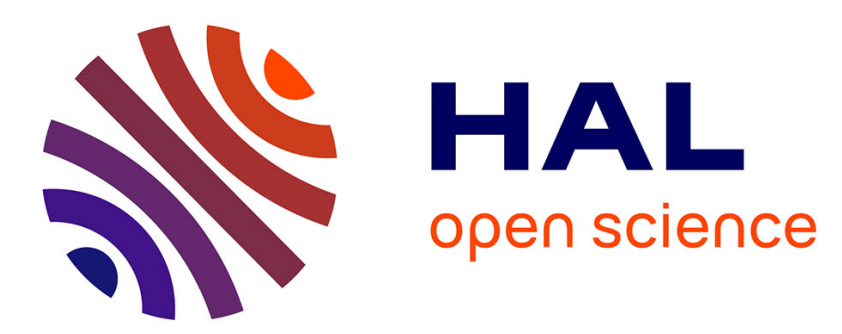

\title{
Application of Semiconductor Whisker Crystals in Low Temperature Electronics
}

R. Baitsar, V. Vainberg, S. Varshava

\section{To cite this version:}

R. Baitsar, V. Vainberg, S. Varshava. Application of Semiconductor Whisker Crystals in Low Temperature Electronics. Journal de Physique IV Proceedings, 1996, 06 (C3), pp.C3-429-C3-434. 10.1051/jp4:1996365 . jpa-00254283

\section{HAL Id: jpa-00254283 https://hal.science/jpa-00254283}

Submitted on 1 Jan 1996

HAL is a multi-disciplinary open access archive for the deposit and dissemination of scientific research documents, whether they are published or not. The documents may come from teaching and research institutions in France or abroad, or from public or private research centers.
L'archive ouverte pluridisciplinaire HAL, est destinée au dépôt et à la diffusion de documents scientifiques de niveau recherche, publiés ou non, émanant des établissements d'enseignement et de recherche français ou étrangers, des laboratoires publics ou privés. 


\title{
Application of Semiconductor Whisker Crystals in Low Temperature Electronics
}

\author{
R.I. Baitsar, V.V. Vainberg* and S.S. Varshava \\ State University "Lvivska Polytechnika", 12 Bandera str., Lviv-13, 290646 Lviv, Ukraine \\ *Institute of Semiconductor Physics, Nat. Acad. Sci. of the Ukraine, 45 Prospect Nauki, 252028 Kiev, \\ Ukraine
}

\begin{abstract}
The properties (electric, galvanomagnetic, tensoelectric) of the whisker crystals such as $\mathrm{Si}-\mathrm{Ge}$ and Te-Se solid solutions, Te, III-V compounds (GaAs, GaP, GaAsP) have been studied in a wide temperature range from 4.2 (for a number of cases from 0.4 ) to $300 \mathrm{~K}$. The set of thermal, magnetic and mechanical sensors based on these materials has been developed. The sensors are favorably characterized by their miniature dimensions, high speed operation and improved metrological performance.
\end{abstract}

\section{INTRODUCTION}

The whisker crystals (WC) along with bulk ones and films find their own application in electronics. In order to fabricate WCs we have used the technique of chemical transport reactions (CTR) in a closed system which enables to obtain a sufficient number of crystals (more than 500) per ampoule as well as to make their doping, including complex, either by introducing couples of impurities involving compensating ones or using the self-compensation effect. WCs have a perfect structure. with a good faceted shape and crystallographic orientation. They need no additional mechanical or other processing and their diameter ranges from a few to hundreds $\mu \mathrm{m}$, the length may reach $3 \mathrm{~cm}$. In spite of the fact that WCs are a suitable model material when studying the crystal growth processes and charge transport mechanisms, their own peculiar properties are still unknown in many aspects that still leaves ahead many device applications to be fulfilled on their basis [1]. Every gas-transport system used to grow crystals has peculiar thermodynamic properties which describe a technological process and must be known to make it well controlled. We used to grow presumably widely spread semiconductors which have a number of advantages. For semiconductor solid solutions one has an opportunity to vary a band structure and energy spectrum of semiconductors (though their composition) and consequently parameters of WCs. It should be noticed that in most cases the temperature profile of the furnace used to grow crystals was linear with fixed temperatures of the source $\left(\mathrm{T}_{\mathrm{s}}\right)$ and crystallization $\left(\mathrm{T}_{\mathrm{c}}\right.$ ) zones. In the case of growing the Te-Se and $\mathrm{GaP}$ crystals $\mathrm{T}_{\mathrm{c}}$ was not fixed, i.e. this zone was in a temperature gradient. The electric contacts were attached to WCs by the method of electric pulse welding a microwire: platinum wire to $\mathrm{Si}-\mathrm{Ge}$ and $\mathrm{GaP}$ and gold to the rest [2].

\section{Si-Ge SOLID SOLUTIONS}

The samples of Si-Ge (up to 12 at. \% Ge) were grown in a sealed quartz crucible in the Si-Ge-Au-B-Br system with two versions of a technological process: I) initial materials are separately taken $\mathrm{Si}$ and $\mathrm{Ge}$; II) an initial material is a synthesized solid solution. The resistivity $(\rho)$ in the first case is determined by the doping impurity $\left(\mathrm{B}_{2} \mathrm{O}_{3}\right)$ concentration and in the second case it is determined by the process of removing the initial 
impurities. The gold plays a role of a growth stimulus via the vapor-liquid-crystal mechanism. The value of $\rho$ is also influenced by zone temperatures $\left(T_{S}, T_{c}\right)$, a carrier $\left(\mathrm{Br}_{2}\right)$ concentration. The typical sample are 3 to $5 \mathrm{~mm}$ long with 20 to $30 \mu \mathrm{m}$ diameter. They have a hexagonal prism shape with the $<111>$ orientation of the growth axis. The sample have a p-type conduction with $\rho=0.005$ to $0.05 \Omega . \mathrm{cm}$ at $300 \mathrm{~K}$ for the first type and $\rho=0.001$ to $0.006 \Omega . \mathrm{cm}$ at $300 \mathrm{~K}$ for the second type. The behavior of $\rho(\mathrm{T})$ over all the range (1.6 to 300 $\mathrm{K})$ for the most samples corresponds to similar $\rho(\mathrm{T})$-dependencies of bulk samples with an impurity concentration from $10^{18}$ to $10^{19} \mathrm{~cm}^{-3}$. The solid solution composition was controlled using the X-ray microprobing. The electric parameters of the samples are listed in Table 1 and illustrated in Fig.1.

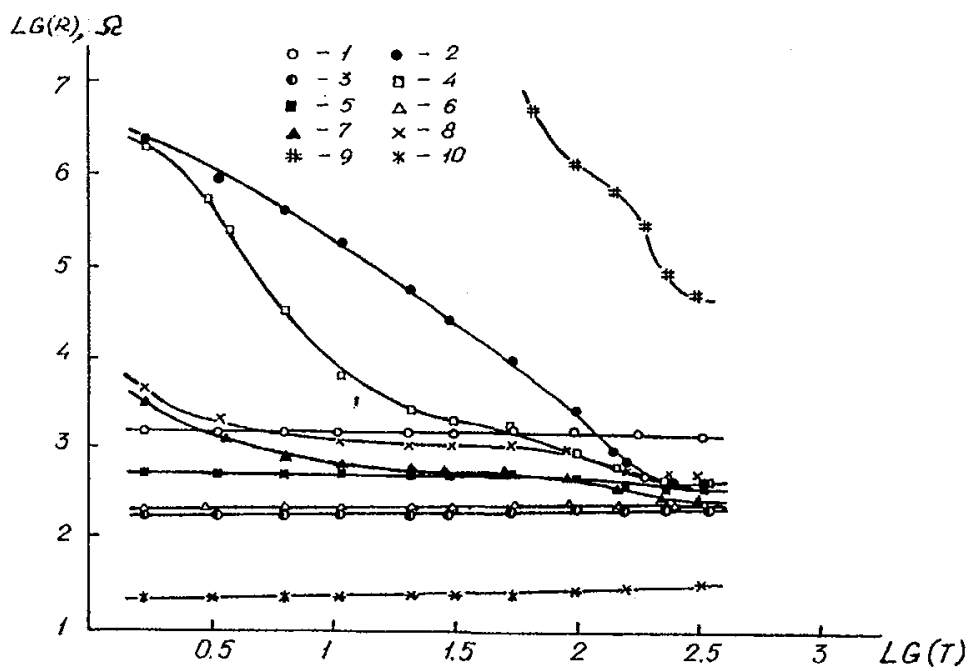

Figure 1: Thermometric characteristics of Si-Ge WCs. The curve numbers correspond to those for samples in Table 1

Table 1

Si-Ge whisker crystal parameters

\begin{tabular}{|c|c|c|c|c|c|c|}
\hline $\begin{array}{c}\text { sample } \\
\text { No }\end{array}$ & $\begin{array}{c}\text { Composition } \\
\text { at. } \% \mathrm{Ge}\end{array}$ & $\begin{array}{c}\mathrm{R}_{300} \\
\Omega\end{array}$ & $\begin{array}{c}\mathrm{R}_{4.2} \\
\Omega\end{array}$ & $\begin{array}{c}\rho_{300} \\
\Omega \cdot \mathrm{cm}\end{array}$ & $\begin{array}{c}\rho_{4.2} \\
\Omega \cdot \mathrm{cm}\end{array}$ & $\rho_{4.2} / \rho_{300}$ \\
\hline SG1 & 0,05 & 1224 & 1284 & 0,0044 & 0,0046 & 1,05 \\
\hline SG2 & 0,22 & 318 & $6 \cdot 10^{5}$ & 0,025 & 46,9 & 1877 \\
\hline SG3 & 0,50 & 193 & 159 & 0,005 & 0,004 & 0,85 \\
\hline SG4 & 0,60 & 360 & $1,2 \cdot 10^{5}$ & 0,019 & 6,05 & 322 \\
\hline SG5 & 1,0 & 348 & 505 & 0,011 & 0,016 & 1,45 \\
\hline SG6 & 3,0 & 230 & 177 & 0,057 & 0,044 & 0,77 \\
\hline SG7 & 4,15 & 279 & 959 & 0,016 & 0,054 & 3,44 \\
\hline SG8 & 4,15 & 483 & 1632 & 0,016 & 0,054 & 3,38 \\
\hline SG9 & 5,35 & $4,5 \cdot 10^{4}$ & - & 2,5 & - & - \\
\hline SG10 & 11,0 & 24,1 & 15,8 & 0,001 & 0,0007 & 0,66 \\
\hline
\end{tabular}


The $\rho$ value and $\rho(T)$ behavior have a complex dependency on the composition (x). The composition fluctuation plays an important role in this case in addition to impurities and defects [3]. For the most samples the parameters $\rho_{300}$ and $\rho_{4.2} / \rho_{300}$ are too small. However, for the compositions with $x>0.2$ the $R(T)$-dependence slope increases with lowering temperature. For $\rho_{300}=0.016 \Omega . \mathrm{cm}$ it occurs when $\mathrm{T}<20 \mathrm{~K}$ and for $\rho_{300} \cong 0.025 \Omega . \mathrm{cm}$ at $\mathrm{T}<100 \mathrm{~K}$. Thus, for these WCs one can observe the $\rho$ (T)-behavior close both to metallic and that which is usually observed in the case of heavily doped and strongly compensated semiconductors [4].

The different behavior of $R(T)$ for the samples under consideration is accompanied by a different character of their low temperature magnetoresistance (MR), $\Delta \rho / \rho$. For the samples with the lowest resistivity $\Delta \rho /$ $\rho$ is in fact independent of the magnetic field $(<0.16 \%)$ and only at $B>1.4 \mathrm{~T}$ it increases to some extent. For the samples with $\rho>0.005 \Omega . c m$ one can observe intervals with a quadratic field dependence $\Delta \rho / \rho=f(B)$, and when $\rho>0.025 \Omega . \mathrm{cm}$ (SG2 sample) a negative MR changing to positive at $\mathrm{B}>1.4 \mathrm{~T}$ appears. One may conclude that this circumstance is connected with formation of an impurity band the conduction via which has a "hopping" nature. It is found that under a weak field $(<0.6 \mathrm{~T})$ the longitudinal MR is larger than the transverse one, while under a strong field this difference is insignificant.

Basing on the low resistivity $\mathrm{Si}-\mathrm{Ge}$ samples we have developed tensoresistors with the tensoresistance coefficient $\left(K=\Delta R / R_{0} \cdot \varepsilon\right)$ more than 140 , where $\Delta R / R_{o}$ is the relative variation of resistance at a given relative tensile or compression deformation, $\varepsilon$. It is indicative that for the samples obtained from the synthesized solid solution (SG1, SG3) the tensosensitivity increases with temperature. WCs with $\rho>0.016 \Omega . \mathrm{cm}$ are attractive from the point of view of application in the semiconductor thermometry.

\section{Te-Se SOLID SOLUTIONS, Te}

The samples have been obtained in the Te-Se- $\mathrm{Br}_{2}$ system. As expected, $\rho$ in this case depends non-monotonously on the composition. We have studied the compositions based on Te up to 2.5 at.\% of the Se content. The electric parameters of the samples are as follows. $\rho_{300}=0.3$ to $0.6 \Omega . \mathrm{cm}, \rho_{4.2}=0.7$ to $4 \Omega . \mathrm{cm}$ for the Te crystals and $\rho_{300}=0.26$ to $0.4 \Omega . \mathrm{cm}, \rho_{4.2}=0.2$ to $2 \Omega . \mathrm{cm}$ for Te-Se. At that the carrier concentration in the Te-Se samples measured in the region of impurity conduction $(\mathrm{T}<100 \mathrm{~K})$ is by an order of magnitude as large $\left(\mathrm{p} \cong 10^{16} \mathrm{~cm}^{-3}\right)$ than that in Te. The Te-Se samples have an unusual temperature dependence of resistivity. Their magnetoresistance is quite sensitive to the composition and may consist both of positive and negative MR parts. These features of low temperature conduction including negative MR can be explained taking into account the Kondo effect related with scattering mechanism caused by localized carrier magnetic moments [5].

Basing on these results the low temperature sensors have been developed. Their thermometric characteristics are described by a simple expression, $\mathrm{R}=\mathrm{A}-\mathrm{B} \cdot \lg \mathrm{T}$, where $\mathrm{A}$ and $\mathrm{B}$ are constant values. It is found that, when $\rho_{4.2}=0.9$ to $2.0 \Omega . \mathrm{cm}$ within the temperature range 1.7 to $30 \mathrm{~K}$, this dependence represents a single straight line (Fig.2). Due to the Kondo effect the $R=f(T)$ dependence for all the samples have a minimum at $\cong 30 \mathrm{~K}$. Its temperature position correlates with a maximum of the Hall coefficient curve, $R_{H}(T)$, and both the minimum of $\rho(T)$ and maximum of $R_{H}(T)$ shift at large impurity concentrations toward a higher temperature.

As follows from the MR measurement results MR variation for Te WCs exceeds $100 \%$ under the field $\mathrm{B}>3 \mathrm{~T}(\mathrm{~T}=4.2 \mathrm{~K})$, the $\Delta \rho / \rho=\mathrm{f}(\mathrm{B})$ dependencies being quite linear, which enables to develop magnetic field sensors based on such crystals [6]. 


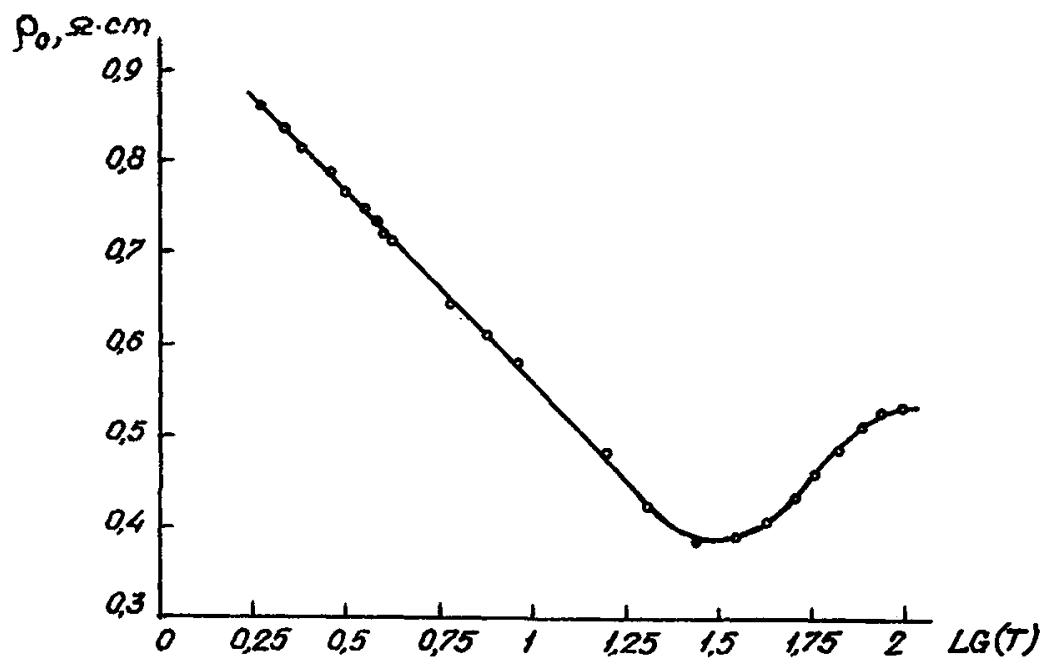

Figure 2: Resistivity vs temperature dependence for the Te WC

\section{III-V COMPOUNDS}

The GaAs, GaP and GaAsP whisker crystals have been grown in quartz crucibles from synthesized materials. The doping impurities are $\mathrm{S}, \mathrm{Zn}$ and $\mathrm{Cu}$. The main non-controlled contamination is Si coming from quartz. The doping level is quite high, $10^{17}$ to $10^{19} \mathrm{~cm}^{-3}$. One of essential features for such crystals is that one has an opportunity to obtain them with a ribbon shape $(\mathrm{RC}),<211>$ growth axis orientation and $\{111\}$ facing.

In the case of $\mathrm{GaA}$ and $\mathrm{GaP}$ the $\mathrm{R}(\mathrm{T})$-dependencies represented as $\lg \mathrm{R}$ vs $1 / \mathrm{T}$ have a character indicative of semiconductors which is an activation type, $\operatorname{lgR} \sim \mathrm{E} / \mathrm{kT}$ or $\operatorname{lgR} \sim \mathrm{T}^{-\mathrm{n}}$, where $\mathrm{n}<1$. Two activation parts manifest: high temperature (so called $\varepsilon_{1}$-part), which is related with activation of carriers to the percolation level, and low temperature $\left(\varepsilon_{3}\right)$ related to hopping conduction [4].

Basing on the n-type GaAs ribbon crystals, which are heavily doped and strongly compensated (the compensation ratio is more than 0.9 ) with $\rho=0.02$ to $0.06 \Omega . \mathrm{cm}$, we have developed wide-range low-temperature $(0.4$ to $300 \mathrm{~K}$ ) thermometers with various sensitivity (from 1 to $10 \% / \mathrm{K}$ ) and design [7]. The outline dimensions of sensitive elements $\left(0.05 \times 0.05 \times 0.2 \mathrm{~mm}^{3}\right)$ provide a time constant for the thermometers at the level of ms that is especially important for dynamic measurements of parameters in cryogenic circulation systems. The technique developed enables also to obtain GaAs WCs with a higher $\rho(>100 \Omega . \mathrm{cm}$ ). The GaAs crystals doped with $\mathrm{Zn}$ possess a significant thermal sensitivity only at $\mathrm{T}>77 \mathrm{~K}$, while at lower temperatures they tend to "flattening". Nevertheless, since their temperature resistance coefficient may be quite low $\left(\cong 6.10^{-4} 1 / \mathrm{K}\right)$ and the tensosensitivity remains high ( $\left.\mathrm{K} \mid>100\right)$, then this enables to use them for fabrication of tensoresistors. The shape of a thin flexible ribbon with the 10 to $20 \mu \mathrm{m}$ thickness improves sensitivity to deformation, in particular on curvelinear surfaces.

The thermometric characteristics of $\mathrm{GaP}<\mathrm{Zn}>$ WCs distinguish by a uniform sensitivity over the range 4.2 to $300 \mathrm{~K}: \mathrm{S}=\mathrm{T} \cdot \mathrm{dR} / \mathrm{R} . \mathrm{dT} \cong 1.3$ to 1.6 , and also by the lowest influence of the magnetic field $(\Delta \mathrm{T} / \mathrm{T}<0.05$ $\%$ at $\mathrm{B}=2 \mathrm{~T}$ and $\mathrm{T}=4.2 \mathrm{~K}$ ). It is shown that there is an opportunity to fabricate cryogenic thermometers with high performance on their basis [8]. The thermometric characteristics of some thermometers from this group are shown in Fig. 3 and their parameters are listed in Table 2. 


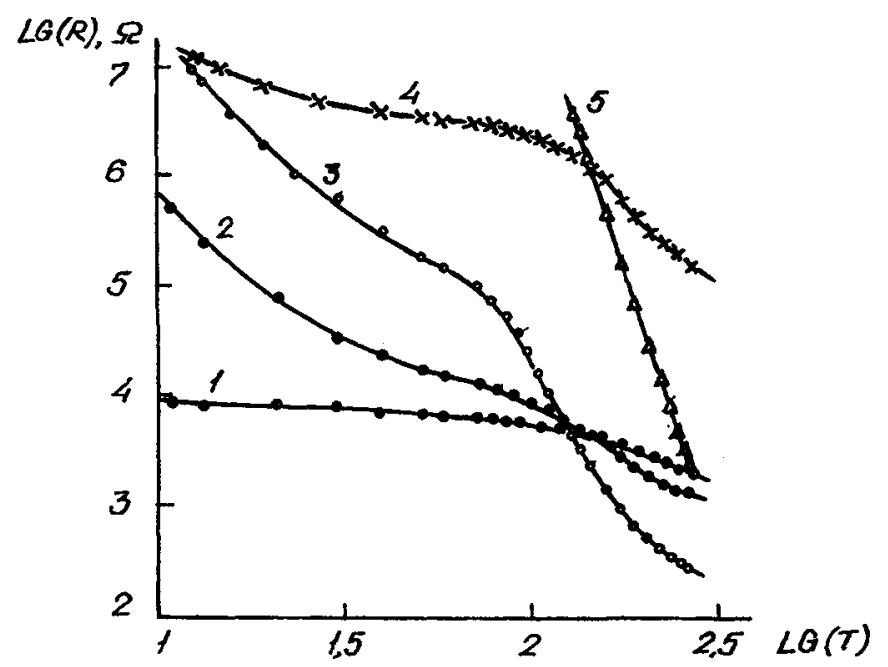

Figure 3: Thermometric characteristics of III-V compound WCs. The curve numbers correspond to those for samples in Table 2

Table 2

III-V compound WCs parameters

\begin{tabular}{|c|c|c|c|c|c|c|}
\hline \multirow{2}{*}{$\begin{array}{c}\text { Sample } \\
\text { No }\end{array}$} & \multirow{2}{*}{ Material } & \multirow{2}{*}{ Impurity } & \multirow{2}{*}{$\begin{array}{c}\text { Conduction } \\
\text { type }\end{array}$} & \multirow{2}{*}{$\begin{array}{c}\rho_{300} \\
\Omega \cdot \mathrm{cm}\end{array}$} & \multicolumn{2}{|c|}{ MR at B=1.5 T and 77 K } \\
\cline { 6 - 7 } & & & & & longitudinal & transverse \\
\hline 1 & $\mathrm{GaAs}$ & $\mathrm{Zn}$ & $\mathrm{p}$ & 3,8 & - & - \\
\hline 2 & $\mathrm{GaP}$ & $\mathrm{Zn}$ & $\mathrm{p}$ & 0,27 & 0,06 & 0,22 \\
\hline 3 & $\mathrm{GaP}$ & $\mathrm{S}, \mathrm{Zn}$ & $\mathrm{n}$ & 0,07 & 0,05 & 0,05 \\
\hline 4 & $\mathrm{GaAs}$ & $\mathrm{Zn}$ & $\mathrm{p}$ & 120 & 0,05 & 0,22 \\
\hline 5 & $\mathrm{GaAsP}$ & $\mathrm{S}$ & $\mathrm{n}$ & 9,8 & - & - \\
\hline
\end{tabular}

The thermometric characteristics of $\mathrm{GaAs}_{1-\mathrm{x}} \mathrm{P}_{\mathrm{X}}$ WCs $(\mathrm{x}=0.4)$ are described by a single dependence which can be written as $\lg R \sim T^{-n}$, where $n=0.5$ to 0.8 . Their application in thermometry enables to widen a range of temperatures to be measured toward «positive» values.

Thus, the thermometers based on WCs can be used both as high-precision standard means and for wider application. It is interesting to notice the fact established in our experiments that a number of important parameters (thermal sensitivity, magnetoresistance) depend on the WC geometrical factor S/L ( $\mathrm{S}$ is the cross section area, $L$ is the length) which can be quite a useful additional lever to control sensor parameters.

\section{Acknowledgments}

The authors are grateful to Dr. A.S.Ostrovskaya and Dr.P.I.Ostrovskii for help in fabrication of samples. 


\section{References}

[1] Givargizov E.I. Growth of whisker and ribbon crystals from vapor (Nauka, Moscow, 1977) pp.264278.

[2] Varshava S.S., Vainberg V.V., Pribori i Tehnika Eksperimenta No.1 (1980) 268-269.

[3] Varshava S.S., Ostrovskaya A.S., Baitsar R.I., Ukrainskii Fizicheskii Zhurnal 39 (1994) 230-233.

[4] Shklovskii B.I., Efros A.L. Electron properties of doped semiconductors (Nauka, Moscow, 1979) pp.367-389

[5] Vainberg V.V., Varshava S.S., Pelekh L.N., Ukrainskii Fizicheskii Zhurnal 38 (1993) 1830-1836.

[6] Varshava S.S., Pelekh L.N, Vainberg V.V., Sensors and Actuators A, 30 (1992) 55-58.

[7] Varshava S.S., Ostrovskaya A.S., Shcherbai K.S., "Resistance thermometers based on semiconductor whiskers", Semicond Lasers, Microwave IC and Satellite Television, Microelectric Sensors, Sozopol 1621 May 1989, (Sofia, 1989) pp.270-274.

[8] Vainberg V.V., Varshava S.S., Zarubin L.I. et al., Optoelektronika i Poluprovodnikovaya Tehnika No.28 (1994) 33-37. 